\title{
Arbor
}

\section{Un espacio europeo de libertad, seguridad y justicia: la cooperación en el ámbito civil}

\section{Alegría Borrás *}

Arbor CLXXII, 678 (Junio 2002), 291-309 pp.

\section{Antecedentes}

La creación de un espacio europeo de libertad, seguridad y justicia en el ámbito civil ha recibido un impulso decisivo con el Tratado de Ámsterdam, pero no se trata de una materia absolutamente nueva. En efecto, el art. 220 TCE en su versión original de 1958 dispone que los Estados miembros «entablarán en tanto sea necesario, negociaciones entre sí a fin de asegurar a favor de sus nacionales», entre otras cosas, para «la simplificación de las formalidades a que están sometidos el reconocimiento y la ejecución recíprocos de las decisiones judiciales y de los laudos arbitrales». En aquel momento, el Derecho internacional privado ocupaba un lugar marginal en la integración europea y por eso se mantenía en el ámbito estrictamente intergubernamental ${ }^{1}$. No obstante, es destacable la importancia de un instrumento concluido al amparo de esta disposición, el Convenio de Bruselas de 29 de septiembre de 1968 sobre competencia judicial y ejecución de decisiones en materia civil y mercantil ${ }^{2}$. Merece destacarse que el Protocolo de Luxemburgo de 1971 ha permitido que se haya creado un importante cuerpo de jurisprudencia del Tribunal de Justicia de las Comunidades Europeas interpretando el Convenio de Bruselas de $1968^{3}$.

Un nuevo paso se dio con el Tratado de Maastricht de 1992. El Titulo VI del Tratado de la Unión Europea se refiere a la cooperación en los asuntos de justicia e interior, lo que demuestra un mayor interés hacia el Derecho internacional privado, que se corresponde con la evolución y ampliación de los objetivos de la Comunidad. Es así como pudo decirse 
que «resulta previsible que el último decenio del siglo XX sea, para el Derecho internacional privado de los países europeos, el del Derecho comunitario» ${ }^{4}$, lo que adquiere una proyección impensable en el primer decenio del siglo XXI.

El art. K.1, apartado 6, disponía que corresponde «desarrollar la cooperación estrecha en el ámbito de la justicia» $y$, a los efectos que aquí interesan, «la cooperación judicial en materia civil», facultando al Consejo a celebrar Convenios, recomendando su adopción a los Estados miembros según sus respectivas normas constitucionales. Se encuadra, pues, en el denominado «Tercer Pilar», utilizando un término, «cooperación judicial en materia civil» ${ }^{5}$, que adolece de gran ambigüedad, que se incorpora después al Tratado de Ámsterdam ${ }^{6}$.

Pese a mantenerse el art. 220, fue sobre la base del art. K.3 que se concluyeron dos Convenios, habiéndose dado como único argumento para ello que se trataba de una base jurídica más específica. Estos dos Convenios son el convenio sobre notificación o traslado en los Estados miembros de la Unión Europea de documentos judiciales y extrajudiciales en materia civil y mercantil, de 26 de mayo de $1997^{7}$, y el Convenio sobre competencia judicial, reconocimiento y ejecución de resoluciones en materia matrimonial y de responsabilidad parental sobre los hijos comunes, de 28 de mayo de $1998^{8}$, el denominado Convenio "Bruselas II», por su parentesco con el convenio de Bruselas de 1968. Aunque firmados por los quince Estados miembros, ninguno de los dos llegó a entrar en vigor por la incidencia del Tratado de Ámsterdam.

Pero hay que señalar que en este periodo, además, se firmó el 23 de noviembre de 1995 el Convenio relativo a los procedimientos de insolvencia, sobre la base del art. $220 \mathrm{TCE}$, sólo firmado por 14 Estados, después de un largo y complejo recorrido. Tampoco este Convenio llegó a entrar en vigor.

\section{El presente}

\section{La nueva base jurídica: los arts. 61 c) y 65 TCE}

El presente arranca del Tratado de Ámsterdam ${ }^{9}$. El Título VI del TUE ha quedado reducido a las «disposiciones relativas a la cooperación policial y judicial en materia penal», que pasaron a ser los nuevos artículos 29 a 42 del TUE, mientras que en el TCE se ha introducido un nuevo Título IV, incluyendo los arts. 61 a 69 , que se denomina «Visados, asilo, inmigración y otras políticas vinculadas a la libre circulación de personas», título poco 
Un espacio europeo de libertad, seguridad y justicia

adecuado pero que muestra el carácter instrumental de estas disposiciones. El nuevo Título IV hace efectivo el art. 2 del TUE, que prevé el mantenimiento y desarrollo de la Unión Europea «como un espacio de libertad, seguridad y justicia». Pero la diversidad de materias incluidas en el mismo condujo, una vez más, a que se prestara mucha más atención a los aspectos relativos a los visados, asilo e inmigración, en cuanto aspectos de Derecho público que afectan a la movilidad de las personas que a las «otras políticas vinculadas a la libre circulación de personas».

Dentro del Título IV, dice el art. 61 que «a fin de establecer progresivamente un espacio de libertad, de seguridad y de justicia, el Consejo adoptará», entre otras, "c) medidas en el ámbito de la cooperación judicial en materia civil, de conformidad con el art. 65». El art. 65 concreta la cooperación judicial en materia civil y, en su parte inicial, dice textualmente que «las medidas en el ámbito de la cooperación judicial en materia civil con repercusión transfronteriza que se adopten de conformidad con lo dispuesto en el art. $67 \mathrm{y}$ en la medida necesaria para el correcto funcionamiento del mercado interior, incluirán ...», pasando a enumerar después cuales son estas medidas.

El examen del ámbito sustantivo del art. 65 pone de relieve su perspectiva finalista, pues se refiere a «mejorar y simplificar», a «fomentar la compatibilidad» y a «eliminar obstáculos». De ahí resulta que su alcance $y$, en consecuencia, la competencia atribuida al Consejo es muy amplia. La propia imprecisión de los términos de estas disposiciones propicia una interpretación extensiva de la competencia atribuida.

En el apartado a) las medidas previstas se refieren a mejorar y simplificar las medidas relativas a traslado de comunicaciones y ejecución de decisiones, ambas cuestiones ya reguladas en el ámbito comunitario con anterioridad ${ }^{10}$ y con la peculiaridad en el segundo caso de que es una materia que también aparece en el art. $293 \mathrm{TCE}^{11}$. Además, se incluye también la obtención de pruebas, que ha sido objeto del más reciente Reglamento comunitario.

El apartado b) del art. 65 da un paso más, pues pretende «fomentar la compatibilidad» de las normas sobre «conflicto de leyes y de jurisdicciones», términos que aparecen por primera vez en el Tratado y sin que resulte claro el significado de «fomentar la compatibilidad», aunque, en la práctica, parezca estarse interpretando como una unificación de las normas de conflicto, como se verá más adelante al tratar de «Roma II» y de «Roma III», aspecto dudoso frente a la unanimidad en admitir la conveniencia de fomentar la compatibilidad de las normas de conflicto aplicables en los Estados miembros, algunas de cuyas discordancias vienen siendo causadas precisamente por la acción comunitaria precedente. 
Finalmente, en el apartado c) del art. 65 se reitera este fomento de la compatibilidad respecto a «las normas de procedimiento civil aplicables en los Estados miembros», aunque limitado al objetivo de «eliminar obstáculos al buen funcionamiento de los procedimientos civiles», expresión que plantea problemas en torno al alcance de la acción a emprender.

Por una parte, «fomentar la compatibilidad» no se identifica con un objetivo de uniformidad normativa. Pero, por otra parte, «fomentar la compatibilidad» parecería implicar, en principio, que se pretende sólo eliminar desajustes normativos que puedan afectar al buen funcionamiento del mercado. Pero, como se acaba de señalar, el ámbito a que se refieren los tres apartados del art. 65 desborda ampliamente tal objetivo y más lo hacen todavía las acciones emprendidas.

Pero hay que recordar las limitaciones en los objetivos que resultan del encabezamiento del propio art. 65: 1) Se limita a la cooperación judicial en materia civil «con repercusión transfronteriza»; 2) Sólo se realizará esta actuación «en la medida necesaria para el correcto funcionamiento del mercado interior». Esta manifestación enlaza directamente con la vinculación de esta cuestión a la libre circulación de personas, ya que ésta sólo será plenamente eficaz si va acompañada de un espacio judicial único, en el que el ciudadano europeo pueda hacer valer sus derechos de forma rápida y eficaz. No resulta, no obstante, tan clara la vinculación de determinados instrumentos con la circulación de personas. En efecto, esta cuestión se planteó en relación al Reglamento «Bruselas II», ya que determinados criterios de competencia judicial internacional en materia de divorcio incluidos en su texto pueden afectar a ciudadanos no comunitarios y que, por tanto, no se benefician de la libre circulación de personas.

Además, la actuación en el marco del Título IV debiera implicar un límite, derivado del juicio de proporcionalidad, es decir, que la medida sea necesaria y apropiada para lograr tal objetivo, y otro límite derivado del principio de subsidiariedad ${ }^{12}$ Estos datos han de ser tomados en cuenta a la hora de enjuiciar la interpretación extensiva del Consejo y de la Comisión, más aún después del Consejo de Támpere. Estos límites generales, unidos a los límites particulares que se desprenden del art. 65 TCE dan una lectura distinta a la que proporciona la práctica.

\section{Las particularidades de los nuevos instrumentos}

Los textos adoptados en el periodo comprendido entre la entrada en vigor del Tratado de Ámsterdam y el momento actual son los siguientes: 
- Reglamento (CE) $\mathrm{n}^{\circ}$ 1346/2000, del Consejo, de 29 de mayo de 2000 , sobre procedimientos de insolvencia ${ }^{13}$.

- Reglamento (CE) $\mathrm{n}^{\circ}$ 1347/2000, del Consejo, de 29 de mayo de 2000 , relativo a la competencia, el reconocimiento y la ejecución de resoluciones judiciales en materia matrimonial y de responsabilidad parental sobre los hijos comunes ${ }^{14}$ (Reglamento «Bruselas II»)

- Reglamento (CE) $\mathrm{n}^{\circ}$ 1348/2000, del Consejo, de 29 de mayo de 2000 , relativo a la notificación y al traslado en los Estados miembros de documentos judiciales y extrajudiciales en materia civil o mercantil ${ }^{15}$.

- Reglamento (CE) no 44/2001, del Consejo, de 22 de diciembre de 2000 , relativo a la competencia judicial, el reconocimiento y la ejecución de resoluciones en materia civil y mercantil ${ }^{16}$ (Reglamento «Bruselas I»).

- Reglamento (CE) $\mathrm{n}^{\circ}$ 1206/2001, del Consejo, de 28 de mayo de 2001, relativo a la cooperación entre los órganos jurisdiccionales de los Estados miembros en el ámbito de la obtención de pruebas en materia civil y mercantil ${ }^{17}$.

Como medida de acompañamiento puede_citarse la creación de la red judicial europea en materia civil y mercantil por decisión del Consejo de 28 de mayo de 2001, que se aplicará a partir de $1^{\circ}$ de diciembre de 2002 , con excepción de sus arts. 2 y 20 que serán aplicables a partir de la notificación de la decisión a los Estados miembros destinatarios ${ }^{18}$. En definitiva, se trata de instaurar en el orden civil un sistema similar al existente en materia penal y que ha tenido un efecto positivo. No es una materia directamente incluida en el ámbito que nos ocupa, pero que cumplirá, sin duda, un papel positivo en su correcto funcionamiento, ya que se trata de facilitar la cooperación judicial entre los Estados miembros en materia civil y mercantil y ello tanto en los ámbitos cubiertos por los instrumentos en vigor como en aquellos en los que todavía no existe ningún instrumento aplicable.

De los nuevos instrumentos merecen destacarse cuatro características.

1. ${ }^{\text {a }}$ En relación a la base jurídica se ha indicado ya que el Tratado de Ámsterdam mantiene la dualidad de bases jurídicas, es decir, el art. 293 (ex art. 220), que sirve de base, como hasta ahora, para la elaboración de Convenios complementarios entre los Estados miembros, y el nuevo Título IV TCE. De hecho, en todos los textos hasta ahora aprobados se cita como base jurídica el art. 61, c) y el art. 67, apartado 1, diciéndose a continuación que la materia respectiva «entra dentro del ámbito del art. 65 del Tratado». En la práctica, no obstante, a partir de la entrada en vigor 


\section{Alegría Borrás}

del Tratado de Ámsterdam no se menciona el art. 293, sino únicamente el Título IV y, en particular, su art. 65. En definitiva, se quiere atribuir a los tratados complementarios entre los Estados miembros un papel subsidiario, que pretende derivarse del hecho de que el art. 293 dice que las negociaciones a los fines previstos en dicho artículo se entablarán «en tanto sea necesario", necesidad que en la práctica se excluye acudiendo sistemáticamente al art. $65^{19}$. Relegado así el art. 293 a un segundo plano, puede quedar vacío de contenido.

2 . $^{a}$ Una segunda característica a destacar en que en todos los instrumentos hasta ahora adoptados se ha escogido el Reglamento, es decir, el instrumento de mayor obligatoriedad en el ámbito comunitario, lo cual implica que es «obligatorio en todos sus elementos y directamente aplicable en los Estados miembros de conformidad con el Tratado constitutivo de la Comunidad Europea», como se ocupa de precisar cada uno de ellos en su parte final.

De hecho, nada se dice sobre la opción del instrumento de Derecho derivado a través del cual se vaya a poner en práctica el art. 65 , concretamente , la opción entre reglamento y directiva, limitándose a decir que el Consejo podrá adoptar «medidas» en el ámbito de la cooperación judicial en materia civil. En la práctica se está prefiriendo la adopción de reglamentos, teniendo en cuenta la unificación que significan y la rápida entrada en vigor simultánea para todos los Estados miembros. Pero, por otra parte, en el Protocolo sobre la aplicación de los principios de subsidiariedad y de proporcionalidad se dice que, en igualdad de condiciones, son preferibles las directivas a los reglamentos.

Un ejemplo es significativo en relación a la elección del instrumento comunitario a utilizar. Se trata del mencionado Convenio sobre notificaciones de 1997, que en la propuesta de la Comisión se convertía sólo en Directiva, alegando que hay una serie de actuaciones previstas para los Estados que hacen preferible este instrumento. No obstante, una mayoría de Estados y y el dictamen del Parlamento Europeo se inclinaron por un Reglamento, que es como ha sido adoptado. Pero su entrada en vigor exige una serie de informaciones por parte de los Estados miembros, requeridas por el art. 23 del Reglamento en relación a los arts. 3, 4, 9, 10, 13, 14, 15 y 19 del propio Reglamento, informaciones que por el momento son incompletas en relación a los organismos receptores y que, por tanto, en la publicación correspondiente se cuidan de calificar de informaciones «excepcionales» ${ }^{20}$.

Si examinamos «Bruselas I» y "Bruselas II», veremos que igualmente se ha optado por el Reglamento y el argumento para ello es claro, deducible de la sentencia del Tribunal de Justicia que ha dicho que el principio de seguridad jurídica y los objetivos perseguidos por el Convenio de 
Un espacio europeo de libertad, seguridad y justicia

Bruselas «requieren que se garantice la igualdad y la uniformidad de los derechos y obligaciones que del Convenio se derivan para los Estados contratantes y para las personas interesadas con independencia de las normas establecidas al respecto en dichos Estados» ${ }^{21}$, por lo que en materia de ejecución el Convenio establece «un sistema autónomo y completo" ${ }^{22}$. Tales características podrían destruirse por el margen de maniobra que una directiva permite.

Mas curioso resulta aún el caso en relación al Reglamento sobre obtención de pruebas en el extranjero, ya que en el hay que distinguir entre entrada en vigor y fecha de aplicación, por lo que puede plantearse si no hubiera sido mejor una directiva. En efecto, según el art. 24, apartado 1, el Reglamento entrará en vigor el 1 de julio de 2001, pero (apartado 2 ) se aplicará desde $1^{\circ}$ de enero de 2004, con excepción de los arts. 14 (denegación de la ejecución), 19 (normas de desarrollo), 21 (relación con los acuerdos o convenios existentes o futuros ente los Estados miembros) y 22 (comunicaciones a realizar por los Estados miembros antes de 1 de julio de 2003) que se aplicarán a partir de $1^{\circ}$ de julio de 2001 . Se demuestra, por tanto, que aunque un Reglamento no necesita de medidas de transposición, en este caso concreto deben adoptarse una serie de medidas para facilitar la aplicación del Reglamento en el orden interno, ya que constituye una novedad importante en el ámbito de la obtención de pruebas que requiere ciertas adaptaciones de los ordenamientos internos para hacer viable su aplicación.

3. ${ }^{\text {a }}$ La tercera característica a destacar se refiere a la interpretación por el Tribunal de Justicia de los instrumentos adoptados al amparo del art. 65. La comunitarización significa que puede intervenir el Tribunal de Justicia, de acuerdo con lo establecido en el art. 68, estrechamente vinculado al artículo 234 (antes, art. 177), para la interpretación o validez e interpretación de este título y de los actos comunitarios adoptados en su virtud, en relación a asuntos ante una jurisdicción nacional que no sea susceptible de recurso. Hay, no obstante, entre ambas disposiciones una diferencia que debe subrayarse y que tendrá, sin duda, consecuencias prácticas: mientras el art. 234 establece que dicho órgano jurisdiccional «está obligado a someter la cuestión al Tribunal de Justicia», el art. 68 se limita a decir que dicho órgano jurisdiccional pedirá al Tribunal que se pronuncie sobre la cuestión planteada «si estima necesaria una decisión al respecto para poder emitir su fallo» ${ }^{23}$.

Otra cuestión distinta es la planteada por algunos autores ${ }^{24}$ sobre la cuestión de la interpretación "comunitaria» de Convenios no comunitarios, como, por ejemplo, de aquellos Convenios de La Haya en que son parte todos los Estados miembros de la Comunidad, entendiendo que 
ello es una exigencia de la integración. Esta idea es sugerente a primera vista, pero también podría ser considerada contraria al Convenio de Viena sobre Derecho de los tratados (art. 31), que tiene como elemento fundamental la expresión auténtica del consensus in idem de los Estados parte en el tratado, que se concreta en el texto del tratado que expresa la voluntad común ${ }^{25}$ y que, en cuanto tal, no puede ser objeto de interpretaciones particulares para un grupo de los Estados parte en tal Convenio. Otra cosa distinta es la posibilidad de celebrar acuerdos inter se dentro de ciertos límites, lo que, en el ámbito comunitario, se traduciría en la adopción de un acto de Derecho derivado que fuera más allá que el Convenio, siempre que no significara una violación de dicho Convenio y así, por ej., si todos los Estados miembros llegaran a ser parte en el Convenio de La Haya de 1996, nada impediría que se adoptara un acto de Derecho derivado, preferentemente un reglamento, en que en materia de protección de niños se estableciera un procedimiento de exequátur similar al contenido en «Bruselas II» y un sistema de cooperación de autoridades más estrecha.

4. ${ }^{\text {a }}$ Una última cuestión a resaltar se refiere al ámbito de aplicación del nuevo texto y a las consecuencias de los instrumentos adoptados, lo cual comporta, a su vez, referirse a la situación de Dinamarca y a los vínculos del sistema de «Bruselas I» con el Convenio de Lugano.

Por lo que se refiere a la situación de Dinamarca, debe recordarse que aunque es miembro de la Comunidad Europea quedó absolutamente fuera del Título IV del Tratado, a diferencia de lo que ocurre con Irlanda y el Reino Unido que ejercieron el opting-in previsto y que les ha permitido, hasta la fecha, incorporarse a todos los instrumentos comunitarios adoptados sobre esta base jurídica. En esta situación se sigue aplicando el Convenio de Bruselas en relación a Dinamarca. Esta es la razón por la que deberá revisarse y ponerlo en línea con el Reglamento, incluyéndose en la negociación también la celebración de Convenios que reproduzcan los demás Reglamentos adoptados sobre esta base jurídica.

Por lo que se refiere al Convenio de Lugano, debe recordarse su origen. El Convenio de Bruselas constituyó un éxito y de ahí que los Estados miembros de la Asociación Europea de Libre Cambio estuvieran interesados en tener un texto igual al concluido entre los Estados miembros de la Comunidad Europea, ya que siendo el Convenio de Bruselas un Convenio complementario entre los Estados miembros de la Comunidad, no era posible la adhesión de otros Estados y, por tanto, era necesario un nuevo texto. Este es el origen del Convenio de Lugano de 16 de septiembre de 1988, el denominado "Convenio paralelo», relativo a la competencia judicial y a la ejecución de resoluciones judiciales en mate- 
ria civil y mercantil ${ }^{26}$, del que, además de los quince Estados miembros de la Comunidad, son parte Islandia, Noruega, Suiza y Polonia, Estado este último que se adhirió recientemente en virtud del proceso de adhesión previsto en el art. 62 del propio Convenio.

Esta es la razón por la que, en 1998, se decidió abordar una revisión conjunta de los Convenios de Bruselas y Lugano, tratando de aproximar aquellas disposiciones que diferían en alguna medida ${ }^{27}$. Pero este ejercicio conjunto no pudo continuar en el momento de la entrada en vigor del Tratado de Ámsterdam, que impedía tal tipo de actuación. No obstante, la modificación sustancial estaba prácticamente concluida y existía un acuerdo en no introducir cambios importantes. Adoptado el Reglamento «Bruselas I», debe ahora negociarse la revisión del Convenio de Lugano, que puede culminar en un plazo breve.

\section{El futuro}

\section{El Programa de reconocimiento mutuo}

En el Consejo de Támpere (15 y 16 de octubre de 1999) se decidió que «la piedra angular» del camino para simplificar el reconocimiento y ejecución de sentencias en materia civil y mercantil la constituía el principio de reconocimiento mutuo, invitando al Consejo y a la Comisión a adoptar un programa de medidas para llevarlo a la práctica. Este proyecto recibió un impulso decisivo en el Consejo informal celebrado en Marsella, durante la presidencia francesa $\left(2^{\circ} \text { semestre de } 2000\right)^{28}$.

$\mathrm{El}$ objetivo final pretendido es la supresión del exequátur en Europa, de tal forma que una sentencia dictada en otro Estado miembro sea reconocida y ejecutada en los demás Estados miembros sin ser sometida a ningún trámite ni control (las denominadas medidas intermedias), lo cual constituye un cambio fundamental respecto a la situación general ${ }^{29}$ y que comporta hacer caer todas las barreras, incluida la del orden público, como última salvaguarda que los Estados siempre se reservan ${ }^{30}$ y sobre la que se cumplimentó un cuestionario, del que resulta que es necesaria una cierta armonización de determinados aspectos del Derecho procesal interno, sin lo cual difícilmente podrá prescindirse de tal control ${ }^{31}$.

De hecho, el Programa es fundamental para los próximos tiempos, pues marca el camino a seguir. Los datos esenciales a destacar serían dos: la forma en que se procederá y las etapas para conseguir la supresión del exequátur. En cuanto a la forma en que se procederá, se toma 


\section{Alegría Borrás}

como punto de partida el estado actual de la situación, distinguiendo entre el primer grado, que sería el alcanzado en el Convenio de Bruselas de 1968 y en el Reglamento «Bruselas II» y el segundo grado alcanzado en el Reglamento «Bruselas I», en cuanto significa un paso más avanzado en este camino. En cada una de las diferentes materias ya incluidas en tales textos se partirá de ellos y en las materias no incluidas, se tratará de avanzar en la forma más rápida posible, sin que sea necesario pasar por el primer grado para alcanzar el segundo. Pero cada materia seguirá su propio ritmo, sin que sea preciso que todas avancen a la misma velocidad, lo que muestra un grado de realismo sobre las dificultades que sobre todo en determinadas materias pueden encontrarse. Como también constituye una muestra de realismo el que se prescinda de establecer fechas para la realización de los trabajos, puesto que «los plazos muy cortos resultan ilusorios y los demasiado largos paralizan a los Estados», estableciéndose únicamente la necesidad de que la Comisión presente un informe sobre los avances al Consejo y al Parlamento Europeo cada cinco años. Piénsese así que el programa puede durar muchos años.

El programa determina cuatro ámbitos de acción: 1) los ámbitos del Derecho civil y mercantil; 2) los ámbitos de Derecho de familia cubiertos por el Reglamento Bruselas II y las situaciones familiares surgidas de relaciones distintas del matrimonio. 3) los regímenes matrimoniales y las consecuencias patrimoniales de la separación de parejas no casadas; 4) los testamentos y las sucesiones, con lo cual se opta decididamente por la inclusión del Derecho de familia y sucesiones en el ámbito del Derecho internacional privado comunitario, pese a las dificultades que el tema tiene y que condujeron, por ej., a la limitación del ámbito de aplicación material del Reglamento "Bruselas II». Veamos a continuación las propuestas que se contienen en el documento y qué es lo que, hasta la fecha, se está haciendo.

\section{La ejecución del Programa}

A partir del momento de la aprobación del Programa, se han iniciado una serie de trabajos, ninguno de los cuales parece pueda ser adoptado en un periodo breve de tiempo.

En el ámbito del Derecho de familia, Francia realizó una propuesta para suprimir el exequátur en materia de derecho de visita ${ }^{32}$, texto que está teniendo numerosas dificultades. La primera, derivada de su vinculación a «Bruselas II» y , en consecuencia, limitarse a los hijos matrimoniales. La segunda, la presentación por la Comisión de una propuesta 
que se ocupa de la protección de los niños en general («Bruselas II bis»), que creará problemas de relación tanto con el Convenio de La Haya de 1980 sobre sustracción de menores, el Convenio de la Haya que más éxito ha tenido hasta la fecha, como con el Convenio de La Haya de 19 de junio de 1996 sobre la competencia, la ley aplicable, el reconocimiento y la ejecución y la cooperación en materia de protección de niños, todavía no en vigor pero que existe la decidida voluntad de ratificar por parte de todos los Estados miembros. En otros ámbitos previstos, como alimentos o parejas de hecho, no hay todavía proyectos específicos, aunque cabe formular ciertas dudas respecto al futuro. Si se trata de alimentos, la proliferación ya existente de instrumentos en la materia, unida a que la Conferencia de La Haya también inicia nuevos trabajos en la materia, no es lo mejor para estos trabajos, si bien se comprende que sería bueno suprimir el exequátur en este ámbito y para el que ya hay dificultades en el orden interno. En cuanto a las parejas de hecho, la sensibilidad es muy grande en los Estados miembros, en que la legislación tanto difiere, tanto en relación al tipo de unión (registrada o consensual) como a la admisión de las uniones homosexuales y su calificación.

En el ámbito patrimonial, la presidencia sueca, en su última reunión del Comité de $\mathrm{D}^{\circ}$ civil presentó un primer documento sobre la supresión del exequátur para los créditos no impugnados, es decir para supuestos similares a lo previsto en el procedimiento monitorio ${ }^{33}$ y en la vía de implantar un Título Ejecutivo Europeo (TEE) en esta materia deberán iniciarse trabajos en fecha muy próxima. En principio, se dice que en nada afectará a los procedimientos internos, pero es obvio que va a implicar un cierto grado de armonización de legislaciones, ya que la base de la supresión del exequátur en esta materia es que conste realmente que el crédito no está impugnado y que un acto de la autoridad del Estado de origen así lo determine, por lo que, por ej., son necesarias ciertas garantías del plazo para la notificación. También en el ámbito patrimonial se desea trabajar en la supresión del exequátur en los casos de demandas de cuantía mínima (small claims), tema que aparece vinculado a la protección de los consumidores y a los métodos alternativos de arreglo de diferencias (ADR o alternative dispute resolution) y sobre el que algunos Estados miembros tienen notables reticencias. De forma mucho más imprecisa, se vislumbra la perspectiva de crear un tipo de ejecución provisional, de instaurar medidas cautelares de nivel europeo e, incluso de un embargo europeo de activos bancarios, incluyendo medidas complementarias para conocer la situación financiera del deudor.

En el establecimiento del programa se observó que en muchas ocasiones sería imposible suprimir el exequátur si no se tomaban ciertas me- 
didas complementarias que puedan facilitar tal paso. En esta línea, en la que se sitúan los ya mencionados Reglamentos sobre notificaciones y obtención de pruebas, así como la mencionada Decisión por la que se crea la Red Judicial Europea. De forma inmediata, se han iniciado los trabajos en materia de asistencia judicial gratuita, sobre la base del Libre verde presentado por la Comisión en febrero de 2000 y las acciones allí previstas, tema del que no se ocultan las dificultades derivadas tanto de la admisión de la misma, como del diferente nivel económico de los Estados miembros y de ahí que se haya optado por preparar una Directiva y no un Reglamento.

Fue precisamente a iniciativa española que entre las medidas complementarias se incluyeran las normas de conflicto de leyes, que incluso habían propuesto algunos su exclusión explícita, perdiendo de vista que la posibilidad indudable de forum shopping derivada del hecho de existir foros alternativos sólo se evita si los tribunales de todos los Estados miembros aplican las mismas normas de conflicto de leyes. Esta línea, que tendría su origen en el Convenio de Roma de 1980 sobre ley aplicable a las obligaciones contractuales («Roma I»), encontraría ahora su continuidad en dos textos. Uno sería un instrumento comunitario sobre ley aplicable a las obligaciones no contractuales («Roma II»), para el cual se han realizado algunos trabajos preliminares ${ }^{34}$, siendo las dificultades políticas las que han impedido que se avance en este camino. El otro sería un instrumento comunitario sobre ley aplicable al divorcio («Roma III»), para el cual únicamente se ha contestado a un cuestionario. Además, en su momento se tratará de transformar el Convenio de Roma de 1980 en un Reglamento, pero parece que ello es prematuro por dos razones: $1^{\text {a }}$ porque sería bueno terminar «Roma II» y ver los avances que se realizan en el ámbito de las obligaciones no contractuales y su posible utilización para «Roma I». $2^{\text {a }}$ Sería bueno esperar a que existiera jurisprudencia del Tribunal de Luxemburgo sobre el Convenio para conocer los problemas y posibles respuestas.

\section{Los efectos ad extra de la comunitarización}

Planteado ya en el momento actual, es un tema de insospechada proyección hacia el futuro. Se trata de saber si la comunitarización tiene una proyección exterior, es decir si existe una competencia externa implícita en el nuevo entorno que se está diseñando ${ }^{35}$. Ya en el Dictamen del Servicio Jurídico del Consejo de 5 de febrero de 1999 se decía que «una vez que la Comunidad haya ejercido sus competencias internas adoptando 
Un espacio europeo de libertad, seguridad y justicia

disposiciones por las que se fijen reglas comunes [al amparo del artículo 65], la competencia comunitaria pasa a ser exclusiva, en el sentido de que los Estados miembros pierden el derecho a contraer, individual o incluso colectivamente, obligaciones con terceros países que afecten a dichas reglas». Es aplicación de la doctrina sentada en el ámbito comunitario a través del denominado «efecto AETR». Pero esta doctrina, sentada en ámbitos puramente económicos, como el transporte o la pesca, ¿puede producir el mismo resultado en materia de Derecho internacional privado? ¿Puede extenderse la interpretación dada para cuestiones vinculadas a la integración económica a las cuestiones jurídicas? ${ }^{36}$. No puede olvidarse que es el propio Tribunal el que exige que la materia objeto del Convenio con terceros Estados se encuentre vinculada de forma inextricable o inseparable de las disposiciones adoptadas para el mercado interior, valoración que no es fácil en los temas aquí abordados.

El punto de partida se encuentra en la distinción de las competencias externas de la Comunidad en explícitas e implícitas ${ }^{37}$. No se encuentran en las primeras las que aquí nos interesan ${ }^{38}$, por lo que hay que referirse a las denominadas «competencias implícitas» o lo que, en forma breve, se denomina «efecto AETR» por la célebre Sentencia del Tribunal de Justicia en que se inicia esta extensión ${ }^{39}$. Esta doctrina ha sido después seguida en mayor o menor medida en numerosos casos ${ }^{40}$. En el dictamen $1 / 76^{41}$ el Tribunal dijo que «la facultad de contraer compromisos internacionales no sólo puede derivarse de una atribución expresa por el Tratado sino que también puede derivarse implícitamente de sus disposiciones». El Tribunal dejó claro, entre otras cosas, que «cuando el Derecho comunitario ha creado para las instituciones de la Comunidad poderes dentro de su sistema interno al objeto de alcanzar un objetivo específico, la Comunidad tiene poderes para contraer los compromisos internacionales necesarios para el logro del objetivo citado, aún cuando falta cualquier disposición explícita a tal fin. Esta circunstancia se da, en particular, en todos aquellos casos en que previamente se ha hecho uso de una facultad interna para adoptar medidas para lograr los fines de políticas comunes, aunque no sólo en este supuesto».

Además, la competencia exterior implícita puede ser exclusiva de la Comunidad o concurrente con la de los Estados. Como ha dicho el propio Tribunal en su dictamen $1 / 78^{42}$, la competencia exclusiva existe sólo cuando responde a una política común, en el caso concreto, la política comercial común en el sentido del art. 113 (hoy art. 133) e implica una obligación financiera que afecta al presupuesto comunitario. Para los demás $\operatorname{casos}^{43}$ no habrá competencia exterior exclusiva, pues no podrá deducirse implícitamente del art. 308 (ex art. 235). Esta es la doctrina que re- 
sulta más claramente del dictamen $1 / 94$, es decir, el propio Tribunal de Justicia reconoce la existencia de una competencia compartida de la Comunidad y de los Estados miembros para participar en la conclusión de los acuerdos GATS y TRIP.

El dictamen últimamente citado resulta particularmente relevante y se incluye, junto con el Dictamen 2/92, en la línea en que se pretende limitar un tanto la interpretación extensiva de las competencias exteriores pretendida por la Comisión. En el caso del Acuerdo de la OMC, el Tribunal se ocupa de precisar que no es suficiente que exista una medida interna para que nazca una competencia exclusiva, sino que es necesario además que dicha medida pudiera verse afectada por las obligaciones asumidas mediante un acuerdo externo. En el caso concreto, el Tribunal no aplica los principios del Dictamen 1/76 al GATS, ya que la realización de la libertad de establecimiento y de la libre prestación de servicios a favor de los nacionales de los Estados miembros no está indisolublemente vinculada a la situación en la Comunidad de los nacionales de Estados terceros o en los Estados terceros a los nacionales de los Estados miembros de la Comunidad ${ }^{44}$. A la misma conclusión llega en relación a los acuerdos TRIP. En el Dictamen 2/92 se dice expresamente que «los Estados miembros, ya actúen individual o colectivamente, no pierden el derecho a contraer obligaciones respecto a Estados terceros más que en la medida en que se hayan establecido reglas comunes susceptibles de verse afectadas por dichas obligaciones» ${ }^{45}$, limitando así notablemente la sentencia AETR, la cual ${ }^{46}$ dice que «cada vez que, para la puesta en práctica de una política común prevista por el Tratado, la Comunidad ha adoptado disposiciones instaurando reglas comunes, los Estados miembros ya no tienen derecho, tanto si actúan individual como colectivamente, a contratar con Estados terceros obligaciones que afecten a dichas reglas». Parece, por tanto, que el Tribunal ha tomado en cuenta las críticas que desde diversos sectores se han formulado al «efecto AETR», en el sentido de que se altera la distribución de competencias, algo que enlaza directamente con la actitud de los Estados miembros, normalmente reticentes a aceptar las competencias implícitas de la Comunidad. Las más recientes decisiones del Tribunal parecen, pues, ir en la línea de respetar la competencia de los Estados para concluir tratados con terceros Estados siempre que no se solape la competencia internacional y la competencia interna ejercida. De ahí, pues, que sólo cuando se trate de cuestiones indisolublemente ligadas» a la medida comunitaria cabe predicar la exclusividad de la competencia, lo que no se da en el caso del dictamen 1/94 entre la libre prestación de servicios a favor de los nacionales o empresas de los Estados miembros y el trato a los nacionales o empresas de Estados no miembros. 
Un espacio europeo de libertad, seguridad y justicia

¿En qué términos puede adaptarse esta doctrina al Título IV, en materia de cooperación civil? Tres son los elementos importantes a considerar en este ámbito: $1^{\circ}$ Que la doctrina de las competencias externas implícitas ha sido elaborada en ámbitos económicos, muy distintos del Derecho internacional privado ${ }^{47} .2^{\circ}$ Que la extensión de la competencia externa de la Comunidad dependerá de los términos de la medida interna. $3^{\circ}$ Que el propio Tribunal se ha ocupado de acotar la posibilidad de una competencia exterior ilimitada. De ahí resultaría que no existe una vinculación necesaria entre la adopción de un instrumento interno «necesario para el correcto funcionamiento del mercado interior» y la conclusión de acuerdos con terceros Estados y, en consecuencia, no puede hablarse de competencia exclusiva ad extra. Será necesario en cada caso ver los límites derivados del ámbito propio del Título IV, estudiar los términos exactos del instrumento extracomunitario y, en último extremo, es necesaria una buena cláusula de desconexión.

\section{Consideraciones finales}

En definitiva, se ve una decidida voluntad política de avanzar por el camino de la supresión del exequátur, es decir, no tratar de forma discriminatoria a las sentencias dictadas por jueces de otros países europeos, de tal forma que prevalezca el principio de confianza mutua y para ello es preciso arbitrar una serie de medios que faciliten la libre circulación de decisiones en materia civil y mercantil. Pero dos consideraciones se imponen:

1. ${ }^{a}$ Si se examina la atención que a la cooperación penal se presta, se observará claramente que la cooperación civil no es objeto de la misma atención y ello se debe tanto a que políticamente resulta más lucida como a que es más fácil que alcance a la prensa. No obstante, debe tenerse en cuenta que en la vida cotidiana del ciudadano europeo es más trascendente la cooperación civil y de ahí la necesidad de avanzar con paso seguro por este camino. Pero es difícil imaginar que los políticos vayan a librar una batalla por la determinación de la fecha de la notificación o por la aceptación del forum non conveniens, por ejemplo, lo cual no es positivo, por las dificultades de carácter técnico que esta materia tiene.

$2 .^{a}$ Lo anterior no obsta a que quepa intuir una decidida voluntad política de avanzar en la vía de la cooperación judicial en materia civil. $\mathrm{Y}$ es que, sin duda, la cooperación en materia penal tiene una mayor repercusión en los medios de comunicación, pero es 
preciso tomar conciencia del hecho de que la cooperación judicial en materia civil afecta muy directamente a la vida cotidiana del ciudadano europeo que, quizá, no es consciente todavía de la incidencia que la integración comunitaria puede tener en los problemas que le afectan más directamente y sin estridencias.

Se trata de un nuevo reto de la integración europea ante el cual las instituciones y los Estados miembros deben asumir sus respectivos papeles, lo cual no es fácil en el ámbito del Derecho internacional privado. Los Estados están entregando una serie de competencias y deben saber a quién y cómo las están cediendo.

\section{Notas}

* Las opiniones expresadas en este trabajo no coinciden necesariamente con las mantenidas como representante de España en la Comunidad Europea para la cooperación judicial en materia civil.

1 Para un estudio amplio y detallado antes del Tratado de Ámsterdam, P. de Miguel, "Integración europea y Derecho internacional privado", Revista de Derecho comunitario europeo, 1997, 2, pp. 413-445.

2 Este texto, como todos los otros textos mencionados que se encuentran en vigor en España o han sido ya publicados en el $B O E$ o en el $D O C E$, según los casos, pueden encontrarse en A. Borrás - N. Bouza - J.D. González Campos - M. Virgos, Legislación básica de Derecho internacional privado, $11^{\mathrm{a}} \mathrm{ed}$, Madrid (Ed. Tecnos), 2001.

3 Sobre las características generales de estos Convenios, A. Borrás, «Los Convenios complementarios entre los Estados miembros de la CEE", Noticias CEE, $\mathrm{n}^{\circ} 12,1986$, pp. 115-118. Las 100 primeras sentencias del Tribunal en M. Virgós - E. Rodríguez Pineau, Competencia judicial internacional y reconocimiento de resoluciones judiciales extranjeras: jurisprudencia del Tribunal Europeo de Justicia, Madrid, 1999. Las sentencias más recientes pueden consultarse en http://europa.eu.int/jurisp/cgi-bin/form.pl?lang=es.

${ }^{4} \mathrm{~S}$. Alvarez, «Pasado, presente y futuro del Derecho internacional privado comunitario", Revista Xiuridica da Universidade de Santiago de Compostela, 1996, vol. 5, pp. 36-37.

5 Aunque lo haya podido calificar de "pariente pobre" de la cooperación judicial, en frase que ha hecho fortuna y confirmada por la realidad en A. Borrás, "La cooperación judicial en materia civil en el Tratado de Maastricht", Perspectivas jurídicas actuales. Homenaje a Alfredo Sánchez Carswell, Madrid, 1995, pp. 385-397; también, A. Borrás, «la cooperación judicial civil», El tercer pilar de la Unión Europea, Madrid, 1997, pp. 231 ss

${ }^{6}$ Así lo señala J.L. Iglesias, "La cooperación judicial en materia civil (CJC) antes y después del Tratado de Ámsterdam", Revista General de Derecho, n 644, mayo de 1998, p. 5851.

7 Publicado, con su informe explicativo del que no consta el autor, en DOCE, C 261, de 27 de agosto de 1997.

8 Publicado, juntamente con el informe explicativo de A. Borrás, en DOCE C 221, de 16 de julio de 1998.

9 Examen más pormenorizado en A. Borrás, «Tratado de Ámsterdam y Derecho internacional privado", Revista Española de Derecho internacional», 1999, 2, pp. 383-426; 


\section{Un espacio europeo de libertad, seguridad y justicia}

A. Borrás, «Hacia la supresión del exequátur en Europa», Cooperación jurídica internacional en materia civil. El Convenio de Bruselas (A. Borrás, dir.) Cuadernos de Derecho Judicial, IV-2001.

10 Son los ya mencionados Convenios de 1997 sobre notificaciones, de 1968 sobre competencia judicial, reconocimiento y ejecución de sentencias en materia civil y mercantil y de 1998 sobre competencia judicial, reconocimiento y ejecución de sentencias en materia matrimonial.

11 Esta duplicidad ha intentado ser salvada por el Servicio Jurídico del Consejo utilizando dos argumentos: $1^{\circ} \mathrm{El}$ encuadramiento del art. 293 en las disposiciones generales y finales le confiere un carácter subsidiario y una función complementaria de otras bases jurídicas. $2^{\circ} \mathrm{Si}$ los autores del Tratado de Ámsterdam reiteraron la materia en el art. 65, ello evidencia que pretendían que la nueva base jurídica fuera aplicable, ya que "permitiría la adopción de medidas comunitarias con prioridad sobre los Convenios celebrados por los Estados miembros".

12 Dice al respecto el art. 10 del Tratado que «la Comunidad actuará dentro de los límites de las competencias que le atribuye el presente Tratado y de los objetivos que éste le asigna. En los ámbitos que no sean de su competencia exclusiva, la Comunidad intervendrá, conforme al principio de subsidiariedad, sólo en la medida en que los objetivos de la acción pretendida no puedan ser alcanzados de manera suficiente por los Estados miembros y, por consiguiente, puedan lograrse mejor, debido a la dimensión o a los efectos de la acción contemplada, a nivel comunitario. Ninguna acción de la Comunidad excederá de lo necesario para alcanzar los objetivos del presente Tratado".

13 D.O.C.E. L 160 , de 30 de junio de 2000.

14 D.O.C.E. L 160 , de 30 de junio de 2000.

15 D.O.C.E. L 160 , de 30 de junio de 2000.

16 D.O.C.E. L 12, de 16 de nero de 2000.

17 D.O.C.E. L 174, de 27 de junio de 2001.

18 DOCE L 174, de 27 de junio de 2001, pp. 25 y ss.

19 Para J.L. Iglesias, «la cooperación judicial en materia civil (CJC) antes y después del Tratado de Ámsterdam", Revista General de Derecho, n 644, mayo 1998, 5852 y 5858 , la delimitación entre ambas disposiciones «es de escaso valor y puramente formal puesto que no obedece a criterios intrínsecos a la materia objeto de la medida comunitaria sino generalmente a razones de oportunidad", convirtiéndose así en una "cuestión doctrinal que, en principio, sólo tiene interés en el ámbito comunitario, para el jurista o para los Estados miembros desde la perspectiva de sus competencias", lo cual no resulta, en todo caso, desdeñable.

20 Información comunicada por los Estados miembros de conformidad con lo dispuesto en el art. 23 del Reglamento (CE) $n^{0}$ 1348/2000 del Consejo, de 29 de mayo de 2000 , relativo a la notificación y al traslado en los Estados miembros de documentos judiciales y extrajudiciales en materia civil o mercantil, D.O.C.E. $\mathrm{n}^{\circ} \mathrm{C} 151$, de 22 de mayo de 2001, pp. 4 y ss., los datos correspondientes a España en pp. 6-7.

21 Sentencia de 15 de noviembre de 1983, Duijnsee $c$. Goderbauer, asunto 288/82, Recueil, 1983 , pp. 3663 y ss., apartado 13.

${ }^{22}$ Sentencia de 2 de julio de 1985, Deutsche Genossenschaftsbank $c$. Brasserie du Pêcheur, Asunto 182/84, Recueil, 1985, pp. 1981 y ss, apartado 17.

${ }^{23}$ Sobre las limitaciones que representa y las características generales, L.N. González Alonso, "La jurisdicción comunitaria en el nuevo espacio de libertad, seguridad y justicia", Revista de Derecho comunitario europeo, 1998, 4, en particular pp. 514-527, donde 
también se hace referencia al que podría denominarse "recurso en interés del Derecho comunitario" que resulta del apartado 3 del artículo 68.

24 Concretamente lo dijo J. Pirrung en el Seminario de Avignon sobre "Bruselas II", «Perspectives d'évolution du droit européen: aspect institutionnel», L'espace judiciaire européen. Actes du Colloque d'Avignon, París, 1999, p. 63. Con anterioridad ya se había hablado de este tema en relación a determinados Convenios como, por ejemplo, con referencia al Convenio de Nueva York de 1958 en materia de arbitraje.

25 J.D. González Campos - L.I. Sánchez Rodríguez - M.P. Andrés, Curso de Derecho internacional público, $2^{a}$ ed. revisada, Madrid, 2002, pp. 307-314.

${ }^{26} \mathrm{Su}$ informe explicativo, redactado por los Sres. P. Jenard y G. Möller puede consultarse en M. Virgós y F. Garcimartín, cit.

${ }^{27}$ Sobre el inicio del proceso puede consultarse la introducción a La revisión de los Convenios de Bruselas de 1968 y de Lugano de 1988 sobre competencia judicial y ejecución de resoluciones judiciales: una reflexión preliminar española (A. Borrás, ed.), Madrid, 1998.

28 Proyecto de medidas para la aplicación del principio de reconocimiento mutuo de las resoluciones judiciales en materia civil y mercantil, publicado en $D O C E \mathrm{n}^{\circ} \mathrm{C} 12$, de 15 de enero de 2001, del que se resalta el cuadro-resumen que aparece en la última página y que resulta muy ilustrativo para comprender el alcance del plan propuesta.

29 Piénsese en nuestro sistema general, en el que la concesión del exequátur compete al Tribunal Supremo, en clara reminiscencia histórica, muy alejada de la cooperación internacional actual en materia judicial.

30 Piénsese que en el proceso de transformación del Convenio de Bruselas en Reglamento, se trató de suprimir esta causa de no reconocimiento o ejecución (art. 27,2) y los Estados no lo aceptaron y así ha pasado la excepción al art. 34, 1.

31 Un buen ejemplo lo ha constituido la Sentencia del Tribunal de Justicia de las Comunidades Europeas en el caso Krombach, que ha puesto de relieve las diferencias entre los ordenamientos alemán y francés en una cuestión fundamental, cual es el derecho de defensa.

32 Publicado en DOCE C 234, de 15 de agosto de 2000.

33 Arts. 812 y ss de la nueva LEC de 2000.

34 Tomando en cuenta, en parte, los trabajos del Grupo Europeo de Derecho internacional privado.

35 Mengozzi, P., «La relazione externe della Comunità Europea e l'Europa dei cittadini", Il Diritto de l'Unione Europea, 1996, pp. 373-390.

${ }^{36}$ Examen detallado de estas cuestiones y los problemas prácticos que se están planteando en A. Borrás, «Efectos respecto a terceros del ejercicio de competencia por la Comunidad europea en el ámbito del derecho internacional privado", Estudios en Homenaje a Antonio Pérez Voituriez , La Laguna (en prensa); A. Borrás, "La incidencia de la comunitarización del Derecho internacional privado en la elaboración de convenios internacionales", Mélanges Isabel de Magalhaes Collaço, Lisboa (en prensa).

${ }^{37}$ En la doctrina reciente, detallado examen de las relaciones exteriores y la jurisprudencia del Tribunal de Justicia en Kaddous, Ch., Le droit des rélations extérieures dans la jurisprudence de la Cour de Justice des Communautés Européennes, Basilea, 1998. Asimismo, muy centrado en la proyección a aspectos económicos, Torrent, M., Derecho y práctica de las relaciones económicas exteriores en la Unión Europea, Barcelona, 1998.

38 Que quedan limitadas a ámbitos como los acuerdos comerciales (art. 133 TCE, es art. 113), acuerdos de asociación (art. 310 TCE, ex art. 238) o relaciones con Organiza- 


\section{Un espacio europeo de libertad, seguridad y justicia}

ciones internacionales (arts. 302-304 TCE).

39 STJCE de 31 de marzo de 1971, Comisión c. Consejo, AETR, Asunto 22/70, en la que se dice que "Cada vez que el Derecho comunitario ha establecido, a favor de las instituciones de la Comunidad, competencia en el plano interno con miras a realizar un objetivo determinado, la Comunidad está investida de la competencia para obligarse internacionalmente en la medida necesaria para la realización de ese objetivo, incluso en ausencia de una disposición expresa a este respecto".

40 Sentencia de 14 de julio de 1976, asuntos 3, 4 y 6/76, Kramer, Recueil, 1976, pp. 1279 ss; Dictamen 1/76, de 26 de abril de 1977, Recueil, 1977, pp. 741 ss, sobre el proyecto de acuerdo relativo a la creación de un fondo europeo de inmovilización de la navegación interior; Dictamen 1/94,, de 14 de noviembre de 1994, Recueil, vol. I, pp. 5267 ss, apartado 85, sobre la OMC y, en particular, en lo que se refiere al comercio de servicios (GATS) y los aspectos comerciales del Derecho de Propiedad intelectual (TRIP); Dictamen 2/94, de 28 de marzo de 1996 sobre la adopción por las Comunidades del Convenio Europeo de Derechos humanos, Recopilación, 1996, I, pp. 1759 ss; Dictamen 2/92, de 24 de marzo de 1995, sobre la competencia de la Comunidad o de una de sus instituciones para participar en la tercera decisión revisada del Consejo de la OCDE relativa al trato nacional, $R e$ copilación, 1995, vol. I, pp. 521 ss, apartado 32.

41 Recueil, 1977, pp. 741 ss, apartados 3 y 4

42 En relación al acuerdo internacional sobre el caucho, dictamen de 4 de octubre de 1979, Recueil, 1979, pp. 287 ss.

${ }^{43} \mathrm{Al}$ respecto, Pocar, F., Diritto dell'Unione e delle Comunità Europea, $6^{\mathrm{a}}$ ed., Milano, 2000, pp. 71-72.

44 Apartado 86, p. 5414. Dice textualmente que «la realización de la libertad de establecimiento y de la libre prestación de servicios a favor de los nacionales de los Estados miembros no está indisolublemente vinculado a la condición a dar en la Comunidad a los nacionales de países terceros o en los países terceros a los nacionales de los Estados miembros de la Comunidad".

45 Apartado 31, en p. 559.

46 En su apartado 17.

47 Así se ocupa de delimitarlo Torrent, R., Derecho y práctica de las relaciones exteriores en la Unión Europea, Barcelona, 1998, p. 35, al indicar que en el ámbito de la Justicia y Asuntos de Interior (JAI) se plantean problemas de relaciones exteriores, de los que no se ocupa, "aunque ciertas consideraciones relativas a la PESC y al cuarto pilar les son aplicables, mutatis mutandis". Bajo el término "cuarto pilar" se incluye "el ejercicio en común de facto dentro del sistema institucional de la Unión de las competencias de los Estados miembros, en particular, pero no exclusivamente, en materia de relaciones económicas exteriores" (Ibid, p. 22 y $149 \mathrm{ss}$ ). Se trata, por tanto, de las materias que no constituyen ni el segundo ni el tercer pilares (PESC y JAI). 